Bruyère, S., Erickson, W., \& VanLooy, S. (2004). Comparative study of workplace policy and practices contributing to disability nondiscrimination. Rehabilitation Psychology, 49(1), $28-38$.

(C) 2004 Educational Publication Foundation

Originally published in Rehabilitation Psychology, a publication of the American Psychological Association (http://www.apa.org/journals/rep/)

This article may not exactly replicate the final version published in the APA/EPF journal. It is not the copy of record.

\title{
Comparative Study of Workplace Policy and Practices Contributing to Disability Nondiscrimination
}

\author{
Susanne M. Bruyère \\ Program on Employment and Disability, Cornell University \\ William A. Erickson \\ Program on Employment and Disability, Cornell University \\ Sara VanLooy \\ Program on Employment and Disability, Cornell University
}

\begin{abstract}
Objective: To assess the impact of disability nondiscrimination legislation on employer practices in the United States and the United Kingdom. Study Design: U.S. and U.K. human resource professionals were surveyed about their experience with implementation of the legislation. Results: Both U.S. and U.K. employers are responding to their respective legislation by making accommodations-adjustments needed by applicants and employees with disabilities.

Conclusions: Rehabilitation psychologists and other health care professionals working with people with disabilities must understand employee rights and employer responsibilities under this legislation, know where employers may have difficulty in responding to an accommodation request, and be familiar with the existing workplace resources and processes that can support an effective response to such requests.

People with disabilities are often underemployed or unemployed, compared with their nondisabled peers - and approximately one in six people has a disability. In the 1990s, many world economies were stronger than they had been for decades. Unfortunately, the unemployment rate of persons with disabilities did not improve concurrently (Wehman, 1998), and in many countries it continues to be disproportionate to that of the general population. In the United States, for example, $34 \%$ of men and 33\% of women with disabilities were employed in 1999 , compared with $95 \%$ of men and $82 \%$ of women without disabilities (Burkhauser, Daly, Houtenville, \& Nargis, 2001). This low employment rate represents a loss of income and social and economic participation for people with disabilities, as well as a significant loss of willing
\end{abstract}


and able talent to both private- and public-sector organizations. This disparity is a result of inequities in a variety of areas including social policy, access to education, training, employment, and society's attitudes. It persists in spite of developments in assistive technologies, innovations in rehabilitation approaches, and enhanced legislative protections.

In an attempt to address this disparity, both the United States and the United Kingdom passed disability nondiscrimination legislation during the 1990s. In the United States, the Americans With Disabilities Act of 1990 (ADA) affords protections in employment, access to goods and services, and public accommodations. ${ }^{1}$ The Disability Discrimination Act of 1995 (DDA) provides similar protections in the United Kingdom. ${ }^{2}$

The ADA became law on July 26, 1990, and provides civil rights protection to individuals with disabilities, both mental and physical, similar to that provided to individuals on the basis of sex, race, national origin, and religion. It guarantees equal opportunities for individuals with disabilities in the areas of employment, state and local government services, public transportation, privately operated transportation available to the public, places of public accommodation, and telephone services offered to the general public. The employment area of the act requires that people with disabilities have an equal opportunity for jobs for which they are qualified. It applies to employers of 15 or more employees. Employers must make prescreening and hiring practices accessible and must make reasonable accommodations to permit qualified individuals with disabilities to perform the essential functions of their jobs in a reasonable manner if the provision of such accommodations does not impose an undue hardship.

The DDA in the United Kingdom gives disabled people ${ }^{3}$ rights in the areas of employment, obtaining goods and services, and buying or renting land or property:

The Act requires schools, colleges and universities to provide information for disabled people and allows the Government to set minimum standards so that disabled people can use public transport more easily. In addition, the Act sets up the National Disability Council and the Northern Ireland Disability Council to advise the Government on discrimination against disabled people. (Minister for Disabled People, 1995, p. 2)

The disabilities covered could be physical, sensory, or mental. The disability must also be substantial and have a long-term effect (that means the disability must last or be expected to last for 12 months). Conditions that have a slight effect on day-to-day activities, but are expected to become substantial, are covered. Severe disfigurement is also classed as a disability. Employers and people who provide goods and services to the public will have to take reasonable measures to make sure that they are not discriminating against people with disabilities. Some people will have to take measures both as an employer and as someone who provides goods and services to the public. The employment provisions of the Act do not apply to entities with fewer than 20 employees (Department for Education and Employment, 1996).

\footnotetext{
${ }^{1}$ Further information is available on the Web (http://www.eeoc.gov/laws/ada.html).

${ }^{2}$ Further information is available on the Web (http://www.legislation.hmso.gov.uk/acts/acts1995/1995050.htm).

${ }^{3}$ The DDA uses the term disabled people (rather than person-first language), so it is used here to reflect the law's actual wording.

(C) 2004 Educational Publishing Foundation. Used with Permission
} 
The potential impact of the provisions of disability nondiscrimination legislation on the labor market as a whole and on the experience of persons with disabilities in particular is very significant, considering that in 2000 only $57 \%$ of the 30.6 million Americans with disabilities between the ages of 21 and 64 were employed (Burkhauser et al., 2001). Interest in addressing the situation for individuals whose disability affects their ability to work is growing in the international arena (Bruyère, 2000b).

A review of the literature suggests that much research remains to be done on the effects of disability antidiscrimination legislation in the workplace, both in the United States and abroad. The most current and comprehensive cross-cultural review of employment policies for individuals with disabilities provides a useful legislative and policy comparison but does not attempt to evaluate the impact of the laws it reviews in the 18 countries studied (Thornton \& Lunt, 1997).

Very little cross-national research has been done in the disability employment arena. As Burkhauser and Daly (1998) noted, very little is known about the labor force experiences of Americans with disabilities and especially how these might compare to those of people with disabilities in other countries. Another proponent of comparative research on the subject is Floyd (1997), whose overview of the challenges facing vocational rehabilitation in Europe recommended the use of comparative studies of policies in different countries to examine their effects on the employment of people with disabilities.

Comparative studies have long been used to verify or dispute social theories. The use of such analysis may seem obvious for anyone wishing to generalize about social processes on a "unit" level (i.e., on the national, regional, or cultural level). As Jowell (1998) stated, "Cross national studies help to reveal not only intriguing differences between countries and cultures, but also aspects of one's own country or culture that would be difficult or impossible to detect from domestic data alone" (p. 168). More specifically, Nowak (1989) pointed out that comparative study is useful even at lower levels of analysis for two reasons: First, it allows for a wider range of variables, and second, it can extend the validity of a generalization through replication of the results.

Nevertheless, unit differences can provide complications for comparative studies. In particular, disability nondiscrimination studies can be complicated by different uses of the term disability. Although disability laws in each country typically define the terms used, each definition is slightly different. Hodges-Aeberhard and Raskin (1997), referring to affirmative action programs, warned that "models in place in one country cannot be imported to another without taking into consideration the differing national conditions" (p. 105).

It is the intent of this cross-national article to present an assessment of the impact of disability nondiscrimination legislation on employer practices in the United States and United Kingdom and to explore from the viewpoint of organizations in these two countries what the remaining barriers and issues are to the employment of people with disabilities, and how to address them. The specific focus here is on the role of rehabilitation psychologists in contributing to these changes. The purposes of this research were to identify how private-sector U.S. and U.K. human resource (HR) professionals have responded to their respective disability (C) 2004 Educational Publishing Foundation. Used with Permission 
nondiscrimination legislation and to determine what rehabilitation psychologists can do to support their critical role in minimizing workplace discrimination for people with disabilities.

For the full impact of disability nondiscrimination legislation to be realized, it is imperative that persons in business be aware of the existence of the law and its implications for hiring, promotion, and other personnel practices. HR professionals are often positioned in businesses to facilitate entry and ongoing success in the workforce. The research approach described here was based on the premise that the implementation of the employment provisions of this legislation falls largely in the realm of the functioning of HR professionals. HR professionals are responsible for recruitment, pre-employment screening, and other workplace practices that affect the hiring and retention of workers with and without disabilities. Further confirming this group's importance is the fact that the median ratio of HR staff to employees is currently about $1.0 \mathrm{HR}$ employees for every 100 workers in every organization in the United States (Bureau of National Affairs, 2001).

\section{Research Methodology}

\section{Survey Methodology}

Survey instrument

Two separate, parallel surveys of similar length, covering issues dealing with the respective employment provisions of the ADA in the United States and the DDA in the United Kingdom, were administered to the members of two different business organization groups. The surveys included items covering the reasonable accommodation-adjustment ${ }^{4} 4$ process; recruitment, preemployment screening, testing, and new employee orientation-induction; health and other benefits of employment; opportunities for promotion-training; disciplinary process-grievance, dismissal, or termination; interaction with labor-industrial-collective bargaining issues and other employment legislation; personnel training on the ADA-DDA; helpfulness of resources used for handling ADA-DDA disputes; and the role of disability management/return-to-work/retention programs in contributing to the accommodation-adjustment process and workplace acceptance of employees with disabilities. ${ }^{5}$

\section{Sampling methodology}

The membership of two large professional HR organizations composed the sample for this project: the Society for Human Resource Management (SHRM), based in the United States, and the Chartered Institute of Personnel and Development (CIPD; formerly the Institute of Personnel Development), based in the United Kingdom.

\footnotetext{
${ }^{4}$ In the United States the term accommodation is used, whereas in the United Kingdom the term adjustment is used, to describe changes to the workplace environment or process to allow an individual to equitably perform a work task or job.

${ }^{5}$ A comparable study has been conducted in the U.S. federal sector, and a comparison of the U.S. private and federal sector survey results (Bruyère, 2000a) is available on the Web

(http://www.ilr.cornell.edu/extension/files/download/comparison16REVISED.pdf).

(C) 2004 Educational Publishing Foundation. Used with Permission
} 
SHRM is the world's largest association devoted to HR management. Founded in 1948 and representing more than 175,000 individual members, the society serves the needs of HR professionals by providing essential and comprehensive resources. SHRM is committed to advancing the HR profession as an essential and effective partner in developing and executing organizational strategy. ${ }^{6}$

With over 116,000 members throughout the United Kingdom and Ireland, the CIPD is the professional body for all those concerned with people management and development. The aims of the CIPD are to advance continuously the management and development of people to the benefit of individuals, employers, and the community at large and to be the professional body for those specializing in advancing the management and the development of people. $7^{7}$

A sample stratified by employer size was drawn from the total population of both the SHRM membership in the United States and the CIPD membership in the United Kingdom. Based on the distribution of members by organization size, a random sample was drawn proportional to the population within size strata. The goal was to have a random sample of individuals from small, medium, and large organizations.

A sample of 1,402 names was provided by the SHRM, and a letter explaining the project was sent 1 week prior to the initial telephone call. Interviews were conducted over the telephone between late summer and early fall of 1998 by the Computer-Assisted Survey Team at Cornell University, using a computer-assisted telephone interviewing system; 813 of the 1,116 eligible respondents participated (a 73\% response rate).

The CIPD members were sent a notification letter and then contacted and interviewed by telephone in early 1999 by Plus4, a U.K.-based survey organization. A response rate of $60 \%$ of the 1,343 eligible contacts was obtained $(n=802)$.

\section{Respondent Characteristics}

From this point forward the SHRM sample is referred to as the U.S. respondents and the CIPD sample as the U.K. respondents. There is representation of employers throughout the size spectrum in both the U.K. and the U.S. respondents. However, it is important to note that there is a significant difference, $\chi 2(4, N=1,612)=124.52, p<.0001$, between the countries in the size of employers represented in the samples. There are significantly more respondents from employers with fewer than 100 employees in the U.K. sample (31\% compared with $16 \%$ in the U.S. sample) and a greater proportion of respondents with 100 to 499 employees in the U.S. sample (28\% compared with $9 \%$ in the U.K. sample). The remaining larger employer size groupings were similar. Because of this difference in samples, issues that might be affected by firm size were also analyzed, restricting the sample to only larger firms of 1,000 or more employees. If the findings were different for this subsample, they are noted in the text. All figures show the overall results for the total sample for each country. The analyses presented in this article used primarily chi-square tests and $t$ tests as appropriate. In cases in which low expected cell counts were

\footnotetext{
${ }^{6}$ More information on the SHRM is available on the Web (http://www.shrm.org).

${ }^{7}$ More information on the CIPD is available on the Web (http://www.cipd.co.uk/).

(C) 2004 Educational Publishing Foundation. Used with Permission
} 
encountered, Fisher's exact test was used in place of a chi-square test. The $p<.05$ significance level was used throughout, applying Bonferroni's adjustment procedure for multiple statistical tests within issue categories where required to control for compounding comparisonwise Type I error rates.

There was no statistically significant difference between countries regarding the number of years of experience the respondents had with their organizations. On average, respondents had been with their companies $81 / 2$ years. Only a small number of respondents (16\%) had been with their companies for fewer than 2 years. Because this research was focused on the impact of disability nondiscrimination legislation in the workplace, it is worth noting that nearly half of the U.S. respondents, and two thirds of the U.K. respondents, had been with their organizations when these pieces of legislation were implemented.

\section{Results}

\section{Response to Accommodation Requirements}

In both the United States and the United Kingdom employers are responding to their respective disability nondiscrimination legislation by making accommodations-adjustments needed by applicants and employees with disabilities. In fact more than $93 \%$ of the respondents noted that their company had made at least 1 of the 11 types of accommodations enquired about. Overall, the accommodations noted by the largest number of respondents (when averaged across both countries) included being flexible in the application of HR policies $(82 \%)$ and making existing facilities accessible (80\%), followed by modifications to equipment $(66 \%)$ and to the work environment (66\%). Some of the least often reported accommodations were in the areas of providing qualified readers and interpreters and making changes in supervisory methods (see Table 1).

There was a statistically significant difference between country responses to making accommodations. The U.K. respondents were more likely to say they had a "need" to make the change in 5 of the 11 accommodations listed. When the sample is limited to those who had a need (or request) to make an accommodation, over $90 \%$ of the U.S. and U.K. respondents said they were able to make the change. However, it is interesting to note that U.K. respondents had a greater tendency to report that they were "not able to" make the accommodation-change than did the U.S. respondents in more than half the categories. When the sample was restricted to large employers (1,000 or more employees) only "providing qualified readers or interpreters" remained significant, with $8 \%$ of the U.K. respondents reporting that they were "not able to" provide this accommodation, compared with only $1 \%$ of the U.S. respondents, $\chi 2(1, N=320)=$ $11.07, p=.0009$. This reported inability to make accommodations in the United Kingdom could be related to the shorter period of time the DDA has been in effect relative to the ADA, resulting in the U.K. respondents' having less familiarity with providing accommodations and/or fewer accommodation resources available to them. 


\begin{tabular}{|c|c|c|c|c|c|c|c|}
\hline \multirow[b]{3}{*}{ Accommodation } & \multicolumn{3}{|c|}{ U.S. (SHRM) } & \multicolumn{3}{|c|}{ U.K. (CIPD) } & \multirow{3}{*}{$\begin{array}{l}\text { Chi-squared test* based } \\
\text { on } 2 \times 2 \text { accommodation } \\
\text { needed/not needed }\end{array}$} \\
\hline & \multicolumn{2}{|c|}{ Needed } & \multirow[t]{2}{*}{ No Need } & \multicolumn{2}{|c|}{ Needed } & \multirow[t]{2}{*}{ No Need } & \\
\hline & Made & $\begin{array}{l}\text { Not } \\
\text { Made }\end{array}$ & & Made & $\begin{array}{l}\text { Not } \\
\text { Made }\end{array}$ & & \\
\hline Made existing facilities accessible & $82 \%$ & $1 \%$ & $17 \%$ & $78 \%$ & $1 \%$ & $21 \%$ & n.s. \\
\hline Restructured jobs or modified work hours & 68 & 0 & 32 & 59 & 2 & 38 & n.s. \\
\hline Made reassignment to vacant positions & 45 & 1 & 54 & 50 & 5 & 46 & $\begin{array}{c}\chi^{2}(1, N=1716)=13.17, \\
p=0.0003\end{array}$ \\
\hline Acquired/modified equipment or devices & 58 & 0 & 42 & 66 & 2 & 32 & $\begin{array}{c}\chi^{2}(1, \mathrm{~N}=1781)=25.34, \\
\mathrm{p}=0.0001\end{array}$ \\
\hline $\begin{array}{l}\text { Acquired/modified examination or } \\
\text { training materials }\end{array}$ & 30 & 1 & 69 & 48 & 3 & 49 & $\begin{array}{c}\chi^{2}(1, \mathrm{~N}=1696)=68.91, \\
\mathrm{p}=0.0001\end{array}$ \\
\hline Provided qualified readers/interpreters & 34 & 0 & 66 & 40 & 4 & 57 & $\begin{array}{c}\chi^{2}(1, \mathrm{~N}=1745)=15.67 \\
\mathrm{p}=0.0001\end{array}$ \\
\hline Been flexible w/ HR policies & 80 & 0 & 19 & 84 & 0 & 16 & n.s \\
\hline Changed supervisory methods & 35 & 1 & 63 & 39 & 3 & 58 & n.s \\
\hline $\begin{array}{l}\text { Parking or transportation } \\
\text { accommodations }\end{array}$ & 66 & 0 & 34 & 60 & 3 & 37 & n.s. \\
\hline Provided written job instructions & 65 & 0 & 35 & 60 & 2 & 38 & n.s. \\
\hline Modified work environment & 62 & 0 & 38 & 70 & 1 & 30 & $\begin{array}{c}\chi^{2}(1, \mathrm{~N}=1783)=21.45 \\
\mathrm{p}=0.0001\end{array}$ \\
\hline
\end{tabular}

When asked, "Who holds responsibility for making the final decision regarding the provision of an accommodation-adjustment," the responses were found to be quite different between the countries. The most common response for the U.S. respondents was "HR staff" (28\%), "other manager or director" (18\%), and "no single party responsible" (17\%). The most common decision maker for the U.K. sample included "other manager or director" $(43 \%)$ and "the immediate supervisor of the employee" (24\%), with 14\% saying there was no single responsible party. These differences may reflect a difference in the structures of organizations within the two countries.

\section{Pre-Employment Accommodations-Adjustments}

Participants were asked about their response to making changes in the recruitment, preemployment screening, testing, and orientation-induction processes to comply with the ADADDA and the degree of difficulty in making these changes. Across the 10 possible areas in which change might need to have been made in this part of the employment process, $52 \%$ to $82 \%$ of all organizations' respondents reported needing to make these individual changes. Approximately one fourth of the respondents reported needing to make all 10 of the changes. The majority of those who made changes in these processes in response to the ADA-DDA indicated that they 
were not difficult to make (see Figure 1). Areas that 1 in 5 or more respondents in both countries indicated were difficult to change included making information accessible for people with visual or learning impairments and making information accessible for people with hearing impairments. There was a statistically significant difference between countries in their response in 4 of the 10 categories for accommodation-adjustment. For example, more U.S. respondents reported difficulty with making information accessible for persons with visual or learning impairments (37\% compared with $24 \%$ for U.K. respondents), whereas more U.K. employers reported difficulty with making recruiting locations accessible (11\% of U.K. respondents compared with $5 \%$ of U.S. respondents).

One encouraging sign was found on the recruiting front with about half of the respondents reporting that their companies proactively recruit persons with disabilities $(51 \%$ in the United States and $47 \%$ in the United Kingdom).

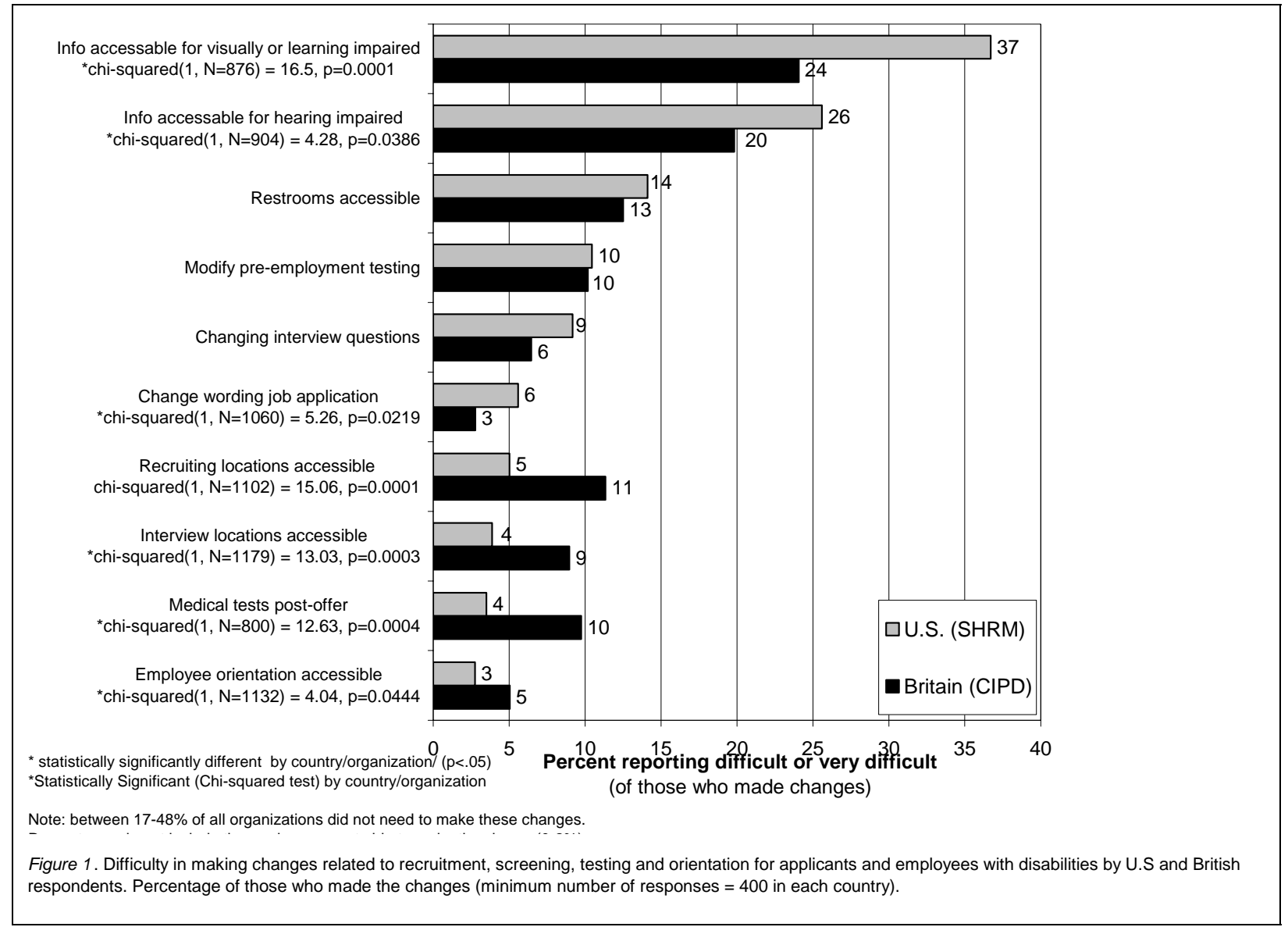

\section{Applicant Interviewing Process}

Respondents were presented with eight ADA-DDA compliance considerations in the applicant interview process and asked how familiar their organizations' interview staff is with each of these elements. The majority of respondents reported familiarity with framing questions about job tasks, restrictions on medical issues, and when to ask about how the applicant would (C) 2004 Educational Publishing Foundation. Used with Permission 
perform job tasks (see Figure 2). Across countries, fewer respondents reported familiarity with the use of teletypewriter-text telephones (TTYs) to set up interviews, use of a reader for a person with a visual impairment, access to sign language interpreters, and adaptation of print materials for people with learning disabilities or visual impairments. The U.S. and U.K. respondents were significantly different in four of the eight areas presented.

More U.S. employers reported familiarity with framing questions to applicants about the ability to perform specific job tasks rather than about the disability ( $89 \%$ of the U.S. HR representatives compared with $82 \%$ of the U.K. respondents), restrictions on eliciting information on medical issues affecting applicants' health and safety on the job (88\% of U.S. compared with $76 \%$ of U.K. respondents), and restrictions on obtaining medical examinations and medical history information ( $80 \%$ of U.S. compared with $72 \%$ of U.K. respondents). More U.K. HR respondents reported familiarity with adapting print materials used in the interview process to large print, diskette, or Braille for applicants with disabilities (40\% of U.K. compared with $30 \%$ of U.S. respondents). These differences, with the exception of the "adaptation of print materials," remained significant when we restricted the sample to large employers (with 1,000 or more employees).

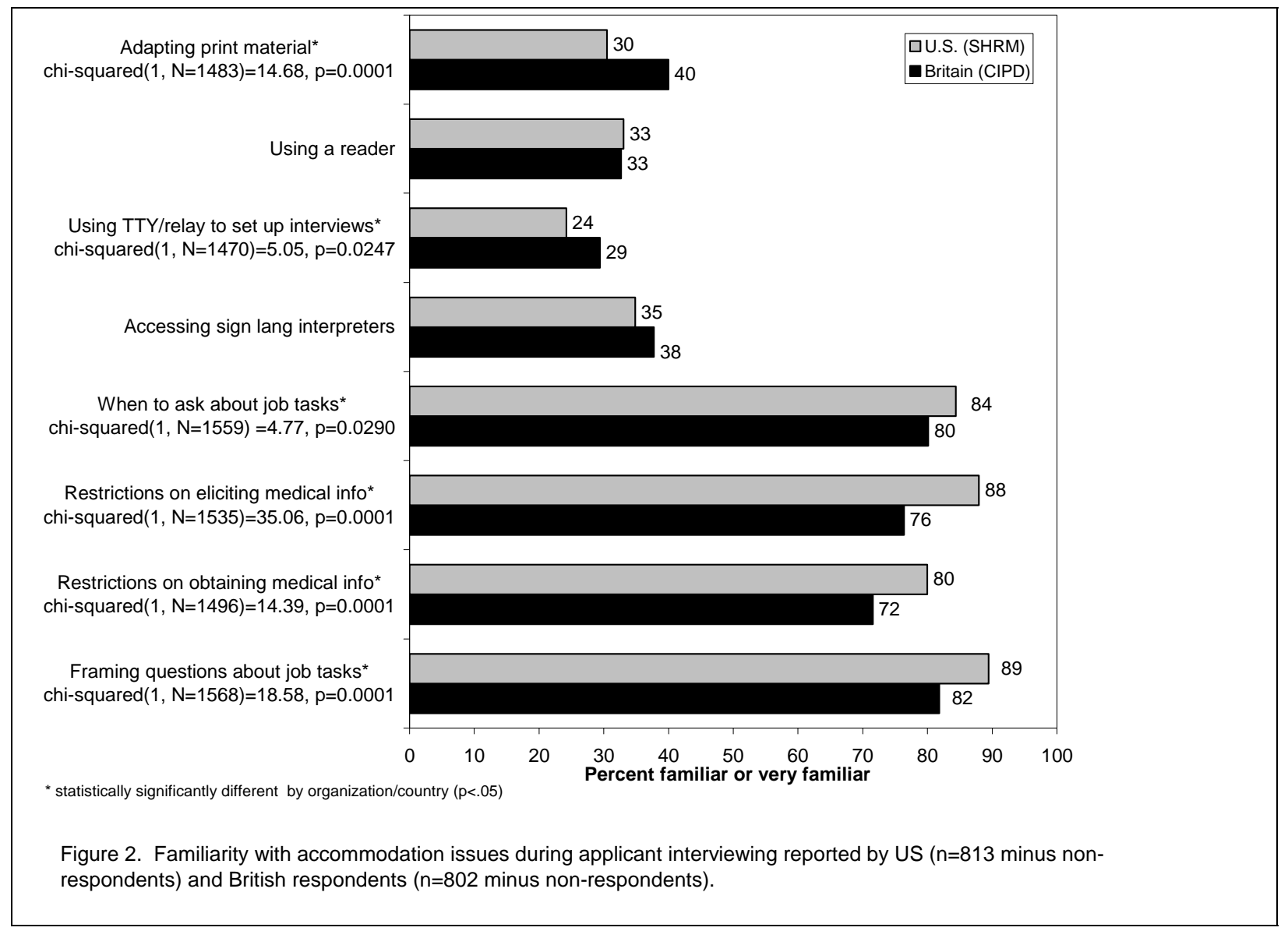

(C) 2004 Educational Publishing Foundation. Used with Permission 


\section{Barriers to Employment and Advancement for People With Disabilities}

Respondents were asked about their perceptions of seven possible barriers to the employment and advancement of people with disabilities in their organization. There was a statistically significant difference between U.S. and U.K. respondents in three of the areas (see Figure 3), although in general the profiles of perceived barriers in terms of overall percentage of response are similar. Surprisingly, the vast majority of U.S. and U.K. respondents did not view monetary issues, including cost of training, supervision, and accommodations-adjustments, as significant barriers for applicants or employees with disabilities, relative to the other areas. The barriers to employment and advancement for persons with disabilities reported by the largest number of respondents included the perception of the lack of related experience (52\% reported by U.S. respondents and $39 \%$ by U.K. respondents) and lack of requisite skills and training in the applicant or employee with a disability ( $41 \%$ reported by U.S. respondents and $27 \%$ by U.K. respondents). The next most often cited barrier was supervisor knowledge of how to make accommodations-adjustments (32\% in the U.S. respondents and $23 \%$ in the U.K. respondents). These were statistically significantly different between the two countries and remained so when we controlled for employer size.

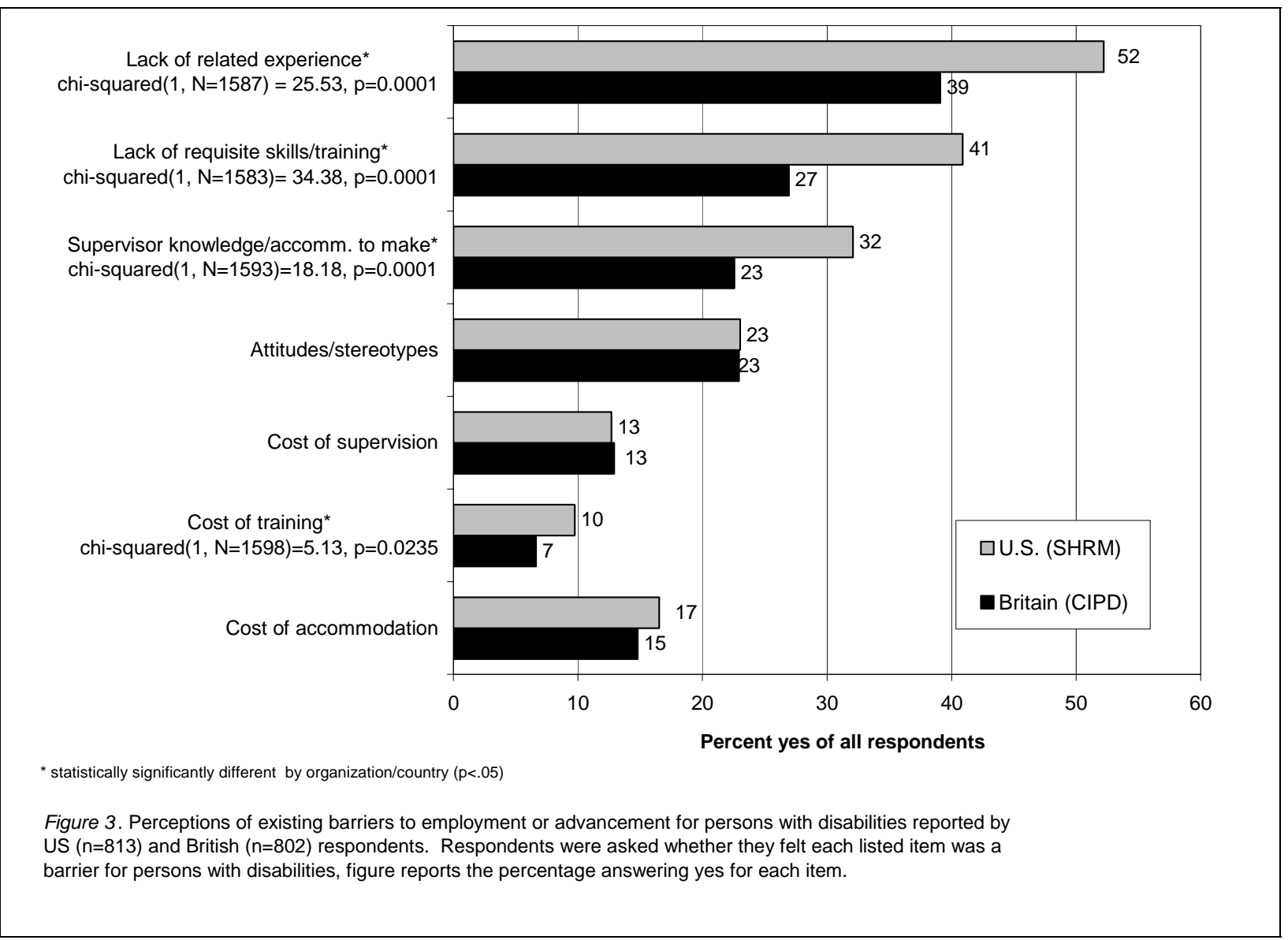

Respondents were also asked to rate the effectiveness of six listed means of reducing possible employment and advancement barriers. The top means identified by respondents of both countries was visible top management commitment $(84 \%)$. The next most often cited means to (C) 2004 Educational Publishing Foundation. Used with Permission 
reduce barriers was staff training; there was, however, a statistically significant difference between countries, with approximately three fourths (77\%) of U.K. compared with two thirds (64\%) of U.S. respondents reporting this as an effective means to reducing barriers, $\chi 2(2, N=$ $1,564)=30.70, p<.0001$. On-site consultation or technical assistance to employers and mentoring were also seen as effective means by $70 \%$ of respondents in the United States and $61 \%$ in the United Kingdom, $\chi 2(2, N=1,552)=16.06, p=.0003$. A notable difference between the countries is a more positive persuasion toward the effectiveness of employer grants among U.K. respondents (68\%) compared with only about one fourth (28\%) of U.S. respondents who viewed the similar concept of tax incentives as an effective means to reducing barriers to employment for persons with disabilities, $\chi 2(2, N=1,484)=243.02, p<.0001$.

In both countries, those surveyed were asked if they had made six specific changes in workplace policies, as well as coworker-supervisor attitudes, to meet the needs of employees with disabilities. Overall two thirds $(66 \%)$ of the U.S. respondents noted they had needed to make all six changes compared with only slightly more than one third of the U.K. respondents (37\%). The U.S. respondents were more likely to say they needed to make each of the individual changes to meet the needs of their employees with disabilities than were respondents in the United Kingdom (a difference of $19 \%$ or more). These differences remained when we controlled for employer size. In both countries, the change noted by the most respondents- $89 \%$ of U.S. versus $70 \%$ of U.K. respondents, $\chi 2(1, N=1,554)=94.87, p<.0001$ - was changing fellow employee or supervisor attitudes toward the employee with a disability. This was also the item that was most often seen as difficult to do, by one third of the respondents in both countries. To help overcome the barriers to employment and advancement faced by people with disabilities, the majority of respondents in the United States and the United Kingdom had made modifications to organizational policies and practices in all but one area (for the United Kingdom). Changes made by more than half of the respondents include ensuring equal pay and benefits, creating flexibility in the performance management system, modifying the return-towork policy, and adjusting medical policies. The one area that the majority (in the United Kingdom) had not modified was changing leave policies; this change was made by only $48 \%$ of U.K. respondents (vs. 79\% of U.S. respondents). All of these changes, with the exception of changing coworker or supervisor attitudes, were seen to be "easy" or "very easy" by the majority of those who made them.

Respondents were asked if they had made five specific accommodations to facilitate equitable access to meetings, promotional or social opportunities, and/or training. Wheelchair access was by far the most often reported accommodation (by nearly three fourths of the respondents). Next most common was allowing time flexibility in test taking provided by nearly half, followed by communication access for people with hearing impairments and access for individuals with visual or learning impairments. Removing volatile or scented substances from the air was reported by slightly more than one fourth of the respondents (28\%). A similar pattern regarding the "need" for accommodations and the actual provision of an accommodation was found between the U.S. and the U.K. respondents. The U.S. respondents were more likely to report a need for wheelchair access $(82 \%$ compared with $77 \%), \chi 2(1, N=1,596)=6.29, p$ $=.0121$, and removing volatile or scented substances from the air ( $35 \%$ compared with $27 \%$ ), $\chi 2(1, N=1,461)=11.55, p=.0007$. The U.K. respondents were more likely to report a need for time flexibility in test taking (55\% compared with $47 \%), \chi 2(1, N=1,543)=11.58, p=.0007$; 
communication access for people with hearing impairments (49\% compared with $42 \%), \chi 2(1, N$ $=1,558)=7.25, p=.0071$; and communication access for people with visual or learning impairments $(46 \%$ compared with $38 \%), \chi 2(1, N=1,553)=10.22, p=.0014$. The vast majority of these accommodations were provided, typically by more than $90 \%$ in both countries, but the U.K. respondents were significantly more likely to respond that they were "unable to provide" the accommodation than were the U.S. respondents by a small but significant margin $(p<.05)$ in each accommodation except time flexibility in test taking. The largest gaps included communication access for people with hearing impairments ( $8 \%$ and $1 \%$, respectively), $\chi 2(1, N=$ $712)=14.99, p=.0001$; communication access for people with visual or learning impairments $(8 \%$ compared with $3 \%), \chi 2(1, N=650)=7.02, p=.0080$; and removal of volatile or scented substances from the air $(14 \%$ and $6 \%$, respectively), $\chi 2(1, N=456)=7.79, p=.0052$. All of these differences, with the exception of communication access for people with visual or learning impairments, remained significant even when the sample was restricted to companies with 1,000 or more employees and so are not related to sample differences in company size. The differences may be related to the greater "need" reported by representatives from the U.K. companies and the shorter period of time the U.K. companies have had to adapt to their more recent legislation.

\section{HR Professionals-Employer Representatives ADA-DDA Training}

The survey asked respondents if their organizations' employees have been trained in 12 ADA-DDA related areas (see Figure 4). Differences in training between the two country groups were statistically significant, with the U.S. informants having conducted significantly more training in 10 of the 12 areas and 7 of the 12 when the analysis was restricted to only larger employers. The areas in which training was most often conducted included nondiscriminatory recruiting (86\% and 80\%, respectively, for the United States and United Kingdom) and confidentiality requirements of the ADA and DDA ( $87 \%$ and $77 \%$, respectively). Areas in which the least training was conducted included accommodations-adjustments for persons with mental health disabilities, limitations to health plans, and training on available written or organizational resources to assist in the accommodation process. The largest gap in training between countries was related to defining essential job functions ( $81 \%$ for the United States, compared with $56 \%$ for the United Kingdom) and the accommodation process ( $72 \%$ for the United States and $55 \%$ for the United Kingdom, respectively). The difference in accommodation training may partially explain why the U.K. respondents were more likely to say they were "not able to provide" certain accommodations than were the U.S. respondents.

Overall, the U.S. respondents reported a wider range of ADA training, with an average of 7.7 of the 12 topic areas $(S D=3.3)$, compared with an average of 6.5 for the U.K. respondents $(S D=4.0)$ on the respective employment disability nondiscrimination legislation requirements under the U.K. DDA, $t(1613)=-6.95, p<.0001$. Much of this difference is due to $11 \%$ of the U.K. respondents' reporting no training in any of these areas compared with only $3 \%$ of the U.S. respondents doing so. There was also a difference in who received the training. Although HR staff received the bulk of the training in both countries, the U.S. HR staff received training in nearly all of the topic areas trained in by their companies $(95 \%, S D=17)$ compared with $78 \%$ $(S D=34)$ of the U.K. respondents, $t(1495)=-12.28, p<.0001$. Managers also received more 
training, $t(1495)=-5.55, p<.0001$, in the topic areas trained in by their companies in the United States $(62 \%, S D=31)$ compared with the United Kingdom $(52 \%, S D=38)$. Occupational safetymedical staff received the least amount of training in both countries with regard to the number of topics companies trained in. These differences were not driven by differences in employer size between the U.S. and U.K. samples, as all remained significant when analysis was restricted to only employers with more than 1,000 employees.

Respondents were asked if they would like to receive more information on each of the training areas. Approximately half of the respondents expressed interest in more information in each of the areas (range $=48 \%$ to $65 \%$ ). The area with the greatest interest in further information was accommodations-adjustments for persons with mental health disabilities, with nearly two thirds of all respondents (65\%) expressing a desire for more information. No significant differences were found by country.

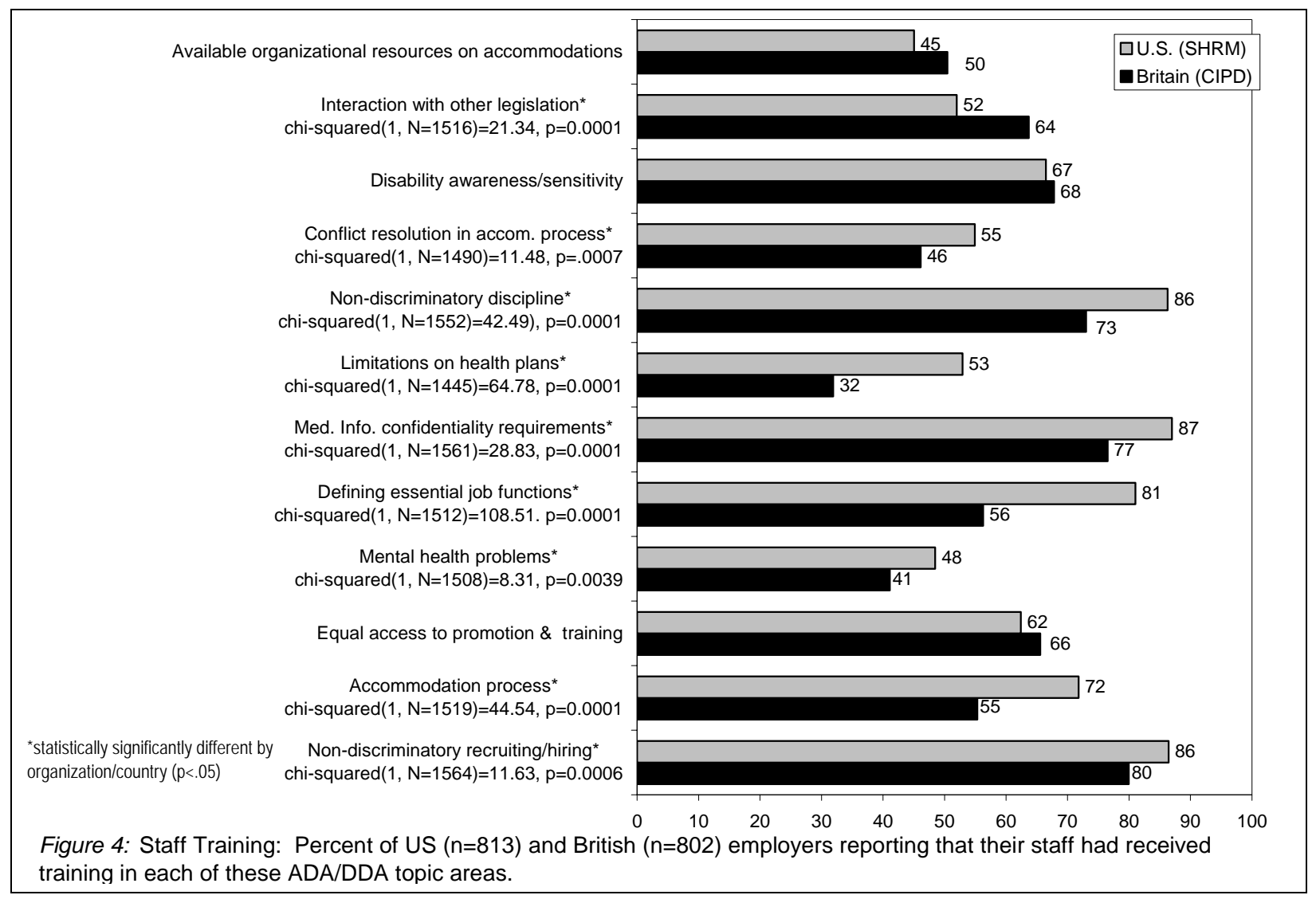

\section{Resources Used to Resolve ADA-DDA Issues}

Respondents were asked about the resources their organizations used to help resolve ADADDA issues and how helpful they found them to be. To make the 12 categories country-specific, the items used for each country differed slightly in terminology and emphasis. Across both countries, legal counsel or advisor was selected as the resource most often used to resolve ADADDA disputes ( $82 \%$ and $61 \%$ for the United States and the United Kingdom, respectively) and 
was rated as helpful by $86 \%$. Next most often used in the United States were professional societies such as the SHRM (65\%; 70\% rated helpful), safety-ergonomics staff $(55 \% ; 74 \%$ rated helpful), and the organization's disability management staff ( $54 \% ; 74 \%$ rated helpful). Other resources used by more than half the U.K. respondents to resolve DDA issues included safety and ergonomics staff (56\%; 83\% rated helpful); 55\% reported using occupational health staff ( $82 \%$ rated helpful). Least often cited resources in the United States were union representatives and alternative dispute resolution (11\% each), and in the United Kingdom, professional societies (27\%) and the Advisory, Conciliation, and Arbitration Service (31\%).

Survey informants were also asked which informational media they used to address their ADA-DDA issues and their degree of helpfulness. There was a statistically significant difference in use between countries in all categories (see Table 2), but respondents from both countries identified print-video resources and on-site consultation and technical assistance as the top two media to address ADA-DDA issues, with three fourths of the users rating them as helpful. The most often cited media in order of use were print-video materials $(75 \%$ and $66 \%$, respectively, for the United States and the United Kingdom), on-site consultation (47\% and 54\%, respectively), and newsletters (45\% and 51\%, respectively). Media reported by the fewest respondents were telephone consultation by U.S. respondents (31\%) and Web sites-electronic mailing lists by U.K. respondents (30\%).

\begin{tabular}{|c|c|c|c|c|c|c|}
\hline Medium & $\begin{array}{l}\text { U.S. } \\
\text { Used }\end{array}$ & $\begin{array}{l}\text { U.K. } \\
\text { Used }\end{array}$ & Chi-squared test & $\begin{array}{c}\text { U.S. } \\
\text { Helpful (1 } \\
\text { or } 2 \text { on a } \\
\text { scale of 1-5) }\end{array}$ & $\begin{array}{c}\text { U.K. } \\
\text { Helpful (1 } \\
\text { or } 2 \text { on a } \\
\text { scale of } 1-5)\end{array}$ & Chi-squared test \\
\hline $\begin{array}{l}\text { Print or video } \\
\text { materials }\end{array}$ & $75 \%$ & $66 \%$ & $\begin{array}{c}\chi^{2}(1, \mathrm{~N}=1597)=15.73 \\
\mathrm{p}<0.0001\end{array}$ & $69 \%$ & $81 \%$ & $\begin{array}{c}\chi^{2}(2, N-1085)=23.37, \\
p<0.0001\end{array}$ \\
\hline $\begin{array}{l}\text { Telephone } \\
\text { consultation/ } \\
\text { information hotline }\end{array}$ & 31 & 40 & $\begin{array}{c}\chi^{2}(1, \mathrm{~N}=1596)=14.6 \\
\mathrm{p}=0.0001\end{array}$ & 67 & 71 & n.s. \\
\hline $\begin{array}{l}\text { On-site } \\
\text { consultation/trainin } \\
\mathrm{g}\end{array}$ & 47 & 54 & $\begin{array}{c}\chi^{2}(1, \mathrm{~N}=1597)=9.46 \\
\mathrm{p}=0.0021\end{array}$ & 77 & 82 & n.s. \\
\hline Web sites/list serve & 35 & 20 & $\begin{array}{c}\chi^{2}(1, \mathrm{~N}=1592)=4.32 \\
\mathrm{p}=0.0376\end{array}$ & 54 & 58 & $\begin{array}{c}\chi^{2}(2, N-476)=19.47 \\
p<0.0001\end{array}$ \\
\hline $\begin{array}{l}\text { Organizational } \\
\text { newsletter }\end{array}$ & 45 & 51 & $\begin{array}{c}\chi^{2}(1, N=1588)=6.65 \\
p=0.0099\end{array}$ & 56 & 70 & $\begin{array}{c}\chi^{2}(2, N=723)=18.24 \\
p=0.0001\end{array}$ \\
\hline
\end{tabular}

\section{Disability Management Programs' Contributions}

Organizational representatives were asked if they had a disability management or return-towork/retention program, and the degree to which that program contributes to compliance with the respective disability nondiscrimination legislation in their country. More than three fourths of the respondents in each of the country groups reported having a program, with slightly more than 
half of these described as a formal program with written policies or procedures. The majority of those who have disability management or return-to-work/retention programs reported that the program contributed to implementation of the ADA-DDA in a number of ways. Nearly three fourths of those with only an informal program reported that it had both contributed to the recognition of the importance of confidentiality of medical information (79\%) and helped to raise the acceptance of employees with disabilities by other employees $(70 \%)$. More than half of the respondents also reported that the informal programs contributed to increasing supervisor awareness of the accommodation-adjustment process $(60 \%)$ and creating an organizational structure for accommodations-adjustments (55\%). In the United States formal programs were found to be more effective in achieving these goals than informal programs, especially with regard to supervisor awareness and creating an organizational structure for accommodation (because of a data collection problem, this information was not collected for the U.K. sample).

\section{Summary and Implications}

It is important that as rehabilitation psychologists, we, along with other health care professionals working with people with disabilities, understand employee rights and employer responsibilities under this legislation. This will enable us to become better educators of and consultants to both the workplace and individuals with disabilities who are our clients and seek our assistance in the employment process. In addition, being knowledgeable about who makes accommodation decisions, where employers go for further information, and the existing workplace resources and processes that can support an accommodation request can assist us in facilitating a workplace intervention for a given individual with a disability.

One of the key points made in this research significant to rehabilitation psychologists is the importance of HR professionals in their role in understanding employment disability nondiscrimination legislation and supporting accommodation requests across the whole employment process. The research described in this report is based on the premise that the implementation of the employment provisions of these pieces of disability nondiscrimination legislation falls largely in the realm of the functioning of HR professionals. HR professionals are responsible for recruitment, pre-employment screening, and other workplace practices that affect the hiring and retention of workers with and without disabilities. The purpose of this research was to identify how HR professionals have responded to this legislation to date and what further can be done to support their very critical role in minimizing workplace discrimination for people with disabilities. It is important to note that the respondents were selected from the two largest HR organizations in their respective countries, SHRM in the United States and CIPD in the United Kingdom, and may respond differently to the needs of employees with disabilities than representatives outside these organizations.

Rehabilitation psychologists who work with global companies may be interested in the similarities and differences in how employers in these two countries have responded to the requirements of their respective employment disability nondiscrimination legislation. Results suggest that organizations in the United States and the United Kingdom are responding positively by making accommodations-adjustments needed by applicants and employees with disabilities. Both U.S. and U.K. informants reported that the costs of training, of supervision, and of accommodations-adjustments for applicants or employees with disabilities are not significant 
barriers to the employment or advancement for persons with disabilities. Wheelchair accessibility and time flexibility in test taking were reported as the types of access most often provided across both countries to ensure that people with disabilities have equitable access to meetings, promotional or social opportunities, and/or training. In both countries, the change most often made but also seen as the most difficult to implement was modifying fellow employee or supervisor attitudes toward the employee with a disability.

For psychologists working with people with visual and hearing disabilities, information about the preparedness of employers to deal with the accommodation requests of people with these disabilities should be of significant interest. Both the U.S. and the U.K. organizations surveyed reported difficulty in responding to requests to make information accessible for people with visual or learning impairments and to make information accessible for people with hearing impairments. Also, an area in which respondents from both countries expressed an interest in gaining further information was accommodations-adjustments for persons with mental health disabilities. These might be areas in which rehabilitation psychologists with appropriate mental health expertise can serve as consultants and trainers, advising business and industry on the specific accommodation needs of these populations. Respondents indicated print resources and on-site consultation and technical assistance as the preferred information media for addressing ADA-DDA issues.

Across both countries, legal counsel or advisor was selected as the resource most often used to resolve ADA-DDA disputes and was also viewed as the most helpful. This suggests that it is imperative that legal advisors, whether corporate in-house professionals or those in the public sector, be well apprised of the requirements of the respective disability nondiscrimination legislation of their country; be knowledgeable about evolving case law; and, even more important, understand the practical implications of what is being asked for and the workplace implications of accommodation-adjustment requests. Safety, disability management, and occupational health professionals also rank high among respondents as persons who are looked to for assistance with accommodation-adjustment requests and implementation of the ADADDA requirements in their respective countries. It is equally important, therefore, that they be well-informed on these requirements. If hired by the employer, this has implications for employer training of these personnel. Less training for these professionals is evidenced from the results of these surveys than is provided for other employer agents such as HR professionals and supervisors. These employer agents could be targeted for specialized information dissemination afforded by the training and consultation interventions of informed rehabilitation psychologists.

The majority of respondent organizations across both countries reported having disability management or return-to-work/retention programs. Such programs appear to contribute to implementation of the ADA-DDA in a number of significant ways such as providing a structure for the accommodation or adjustment process and lessening negative attitudes or stereotypes of coworkers and supervisors. These and similar workplace intervention programs should be further explored and put into practice to support and complement effective disability nondiscrimination legislation. Rehabilitation psychologists can use the resources of such in-house programs to support the accommodation needs of an individual with a disability whom the psychologist is assisting to return to the workplace. 


\section{References}

Bruyère, S. (2000a). Disability employment policies and practices in private and federal sector organizations. Ithaca, NY: Cornell University, School of Industrial and Labor Relations Extension Division, Program on Employment and Disability.

Bruyère, S. (2000b). Managing disability in the workplace. . Equal Opportunities Review, 92, 26-33.

Bureau of National Affairs (2001, June 28). SHRM-BNA No. 66, Human Resources Activities, Budgets, and Staffs: 2000-2001. . Bulletin to Management, 52, S1-S42. 26, Suppl., Part II

Burkhauser, R., \& Daly, M. (1998). Disability and work: The experiences of American and German men. . Economic Review, 2, 17-29.

Burkhauser, R., Daly, M., Houtenville, A., \& Nargis, N. (2001). Economic outcomes of working age people with disabilities over the business cycle: An examination of the 1980s and 1990s. Ithaca, NY: Cornell University, School of Industrial and Labor Relations-Extension Division, Program on Employment \& Disability.

Department for Education and Employment (1996). Disability Discrimination Act 1995 Code of Practice for the elimination of discrimination in the field of employment against disabled persons who have had a disability. London: Her Majesty's Stationery Office.

Floyd, M. (Ed.) (1997). Vocational rehabilitation and Europe. (Disability and Rehabilitation Series 6). London: Jessica Kingsley.

Hodges-Aeberhard, J., \& Raskin, C. (Eds.) (1997). Affirmative action in the employment of ethnic minorities and persons with disabilities. Geneva, Switzerland: International Labor Office.

Jowell, R. (1998). How comparative is comparative research? . American Behavioral Scientist, 42, 168-177.

Minister for Disabled People (1995). A brief guide to the Disability Discrimination Act (Publication No. DL 40). Bristol, England: Disability on the Agenda.

Nowak, S. (1989). Comparative studies and social theory. In M. Kohn (Ed.), Cross-national research in sociology (pp. 34-56). Newbury Park, CA: Sage.

Thornton, P., \& Lunt, N. (1997). Employment policies for disabled people in eighteen countries: A review. York, England: University of York, Social Policy Research Unit.

Wehman, P. (1998). Work, unemployment and disability: Meeting the challenges. . Journal of Vocational Rehabilitation, 11, 1-3. 
The collaboration of many sponsors in the United States and abroad has made this research possible. In the United States, Cornell University worked in collaboration with the Society for Human Resource Management (SHRM), the Washington Business Group on Health (WBGH), and the Lewin Group; in the United Kingdom, Cornell worked in collaboration with the Chartered Institute of Personnel and Development (CIPD) and the Employers' Forum on Disability. The research that occurred with U.S. employers was funded by U.S. Department of Education National Institute on Disability and Rehabilitation Research Grant No. H133A70005 to Cornell University (Susanne M. Bruyère, principal investigator) for a Research and Demonstration Project entitled "Improving Employer Practices Under Title I of the ADA." The U.K. study was funded by the U.S. Department of Education National Institute on Disability and Rehabilitation Research for a Mary E. Switzer Distinguished Research Fellowship to Susanne M. Bruyère (Grant 72-0564834F). CIPD supported the telephone survey effort in Britain for its own membership. We acknowledge the specific contributions of Dianah Worman, CIPD; Allison Branick, SHRM; Susan Scott-Parker, Employers' Forum on Disability; and Bruce Flynn, WBGH, in the design and implementation of this research.

Correspondence concerning this article should be addressed to Susanne M. Bruyère, Program on Employment and Disability, School of Industrial and Labor Relations Extension Division, Cornell University, ILR Extension Building, Ithaca, NY 14853-3901. E-mail:smb23@cornell.edu 